Vol 12, Issue 11, 2019

\title{
COMPARATIVE STUDIES ON PHYSICOCHEMICAL PROPERTIES OF MORINDA CITRIFOLIA GEL AND OINTMENT FORMULATIONS
}

\section{PATAWEEKORN KETKOMOL*, TADSANEE PUNJANON}

Department of Medical Science, Pharmacology and Toxicology Unit, Faculty of Science, Rangsit University, Pathum Thani 12000, Thailand. Email: pataweekorn.k@rsu.ac.th

Received: 11 September 2019, Revised and Accepted: 03 October 2019

\section{ABSTRACT}

Objective: The objective of this study is comparing the physicochemical properties of Morinda citrifolia formulation in various conditions.

Methods: Methanolic fruit extracts of M. citrifolia were used for the preparation of gel and ointment formulations that were evaluated for their phytochemicals, physicochemical, and stability at various conditions.

Results: Phytochemical screening studies of M. citrifolia revealed the presence of bioactive. Furthermore, the evaluation of physical and chemical stability showed that gel formulation was more stable than ointment formulation.

Conclusion: Gel formulation could become a media to be used for its medicinal properties.

Keywords: Formulation, Morinda citrifolia, Phytochemicals, Scopoletin, Stability.

(C) 2019 The Authors. Published by Innovare Academic Sciences Pvt Ltd. This is an open access article under the CC BY license (http://creativecommons. org/licenses/by/4. 0/) DOI: http://dx.doi.org/10.22159/ajpcr.2019.v12i11.35653

\section{INTRODUCTION}

Herbal therapy has been used as traditional medicine as well as in alternative medicine practiced in developing countries. The widespread interestin drugs derived from plants is due to the belief that plants are safe and dependable with fewer side effects. Review of literature revealed that traditional plant drugs are beneficial for several skin-related problems and for wound healing [1-3]. Thailand has been promoting the use of traditional medicine because they are less expensive, easily obtained, and comprehensive, especially in developing countries [4]. Therefore, studies are searching for new drugs extracted from nature to be used for medicinal purposes which are less toxic and with no side effects, unlike chemical drugs. At present, people are more interested in the use of herbs for disease treatment or to be used as a health food supplement. Therefore, the government has made a policy to support research and development of herbal medicines to add value to herbal drug products and to reduce importing drugs from abroad. Furthermore, it is a career option for labor which leads to improving the economy.

Morinda citrifolia commonly known as "Noni" is a small tree native to Southeast Asia. It is also called as Indian Mulberry, Nono or Nonu, Cheese fruit, and Nhau in various cultures throughout the world. Components isolated from noni include scopoletin, octanoic acid, potassium, Vitamin C, terpenoids, alkaloids, anthraquinones, sitosterol, $\beta$-carotene, Vitamin A, flavone glycosides, and linoleic acid. The leaf contains flavanol glycosides, beta-carotene, and iridoid glycosides [5,6]. It is also reported to have a broad range of nutritional and therapeutic values for cancer, infection, arthritis, diabetes, asthma, hypertension, and pain. It also has muscle stimulatory and antihistamine effects along with antibacterial, antiviral, anti-tubercular, antitumor, anthelmintic, analgesic, hypotensive, and immunological effects. Noni has been used as a traditional remedy to treat broken bones, deep cuts, bruises, sores, and wound [7]. The fresh leaf is used for wounds treatment and as a poultice for broken bones in most parts of India [8]. Previous researches have shown that extracts from hexane ethanol and methanol of noni show wound healing capability by adding ligand binding to platelet-derived growth factor and $A_{2 \mathrm{~A}}$ receptors [9]. Previous researches showed $10 \%$ of topical Morinda ethanol extract gel had a significant effect on rat skin excisional wound healing compared to $10 \%$ of povidone-iodine [10]. At the present, products from noni extract have various forms such as capsule, shampoo, soup, and supplement but topical form not a development that topical form, gel, or ointment, detailed information regarding its wound healing capability are not completely documented. The objective of the current study is comparative studies on the physicochemical properties of $M$. citrifolia gel and ointment formulations.

\section{MATERIALS AND METHODS}

Collection of plant material

Fruits of $M$. citrifolia were collected from Mahasarakham province, Thailand, in October 2018. The plant material was authenticated by associate researcher Nirun Vipunngeun in the Department of Pharmacognosy, College of Pharmacy, Rangsit University. A voucher specimen was deposited in our laboratory. They were washed with distilled water, air dried, and then made to a fine powder with a mechanical grinder.

\section{Extraction}

About $1.6 \mathrm{~kg}$ of the powder sample was suspended in $9 \mathrm{~L}$ of methanol on a hot plate $\left(30^{\circ} \mathrm{C}\right)$ for $24 \mathrm{~h}$. After extraction, the sample was filtered using a fine muslin cloth followed by a filter paper (Whatman No. 1) and concentrated at $45^{\circ} \mathrm{C}$ using a rotary vacuum evaporator. The preliminary phytochemical screening was carried out by methanolic extract for the presence of phytoconstituents [11,12].

\section{Phytochemical screening methods}

\section{Anthraquinone}

The extract $(10 \mathrm{~g}$ ) was boiled with $20 \mathrm{ml}$ of $1 \%$ hydrochloric acid and $3 \%$ hydrogen peroxide $2 \mathrm{ml}$ for $15 \mathrm{~min}$. The extract was filtered and then waited until cooled. The extract was added to dichloromethane $10 \mathrm{ml}$ and ammonium hydroxide $3 \mathrm{ml}$. The pink color of the base layer indicated the presence of anthraquinone [13].

\section{Cardiac glycosides}

The extract ( $10 \mathrm{~g}$ ) was boiled with $20 \mathrm{ml}$ ethanol for $15 \mathrm{~min}$. The mixture $(5 \mathrm{ml})$ was placed in an evaporating dish and evaporated to dryness. 
Then, 2\% of 3,5-Dinitrobenzoic acid (Kedde reagent) (1 ml) and $1 \mathrm{M}$ of potassium hydroxide $(0.5 \mathrm{ml})$ were added. Purple color indicates the presence of cardiac [13].

\section{Saponins}

The extract ( $10 \mathrm{~g}$ ) was boiled with $20 \mathrm{ml}$ water for $15 \mathrm{~min}$; the mixture was cooled and mixed vigorously and left for $3 \mathrm{~min}$. The formation of frothing indicates the presence of saponins [13].

\section{Coumarins}

The extract ( $2 \mathrm{~g}$ ) was put into two tubes and covered by filter paper coated with water and sodium hydroxide, respectively, and incubated into a water bath $\left(37^{\circ} \mathrm{C}\right)$ for $5 \mathrm{~min}$. Blue-green color on the filter paper coated with sodium hydroxide under ultraviolet (UV) light (366 nm) indicates the presence of coumarins [13].

\section{Tannins}

The extract (10 g) was boiled with $20 \mathrm{ml}$ water for $15 \mathrm{~min}$. Then, $1 \mathrm{ml}$ of the solution was filtrate added to the $1 \mathrm{ml}$ of $3 \%$ gelatin solution. Precipitation indicates the presence of tannins [13].

\section{Flavonoids}

The extract ( $10 \mathrm{~g}$ ) was boiled with $20 \mathrm{ml}$ ethanol for $15 \mathrm{~min}$. Then, $1 \mathrm{ml}$ of the solution was filtrate added to $1 \%$ ferric chloride. The green-black color indicates the presence of flavonoids [13].

\section{Alkaloids}

The extract ( $10 \mathrm{~g}$ ) was boiled with $20 \mathrm{ml}$ of $1 \%$ hydrochloric acid for $15 \mathrm{~min}$. Then, $10 \mathrm{ml}$ of the solution was added to $10 \mathrm{ml}$ of the dichloromethane. The extract in dichloromethane layer (5 mlS) was separated and added two drops of the alkaloid precipitating reagents. Precipitation of more than $70 \%$ indicates the presence of alkaloids [13].

\section{Procedure for gel base and ointment base formulation preparation} Gel base formation

M. citrifolia fruit extract (10 g) was mixed with $1 \mathrm{~g}$ of Carbopol Ultrezin $50 \mathrm{ml}$ of deionized water. Then, propylene glycol (1.5 g) and paraben $(1.0 \mathrm{~g})$ and triethanolamine $(1.4 \mathrm{~g})$ were added and mixed. The final volume was made up to $100 \mathrm{ml}$ by adding remaining distilled water, also to obtain a gel at the required consistency $[14,15]$. Prepared gel was filled in a container and stored in a place avoiding light. The method described above and the formulae were tabulated in Table 1.

\section{Ointment base formation}

M. citrifolia fruit extract ( $10 \mathrm{~g})$ and white petrolatum $(90 \mathrm{~g})$ were mixed (geometric dilution). The prepared ointment was filled in a container and protected from light. The method described above and the formulae were tabulated in Table 2

\section{Evaluation of physicochemical properties of gel and ointment} formulations

Physical stability test

The physical stability test of the formulations was carried out for 36 days by measuring in the initial ( 0 days) and the $2^{\text {nd }}$ time ( 36 days). At various temperature conditions (1) room temperature $\left(25 \pm 2^{\circ} \mathrm{C}\right),(2)$ cold $\left(4^{\circ} \mathrm{C}\right)$, and (3) heating-cooling cycle (kept in a hot oven at $45^{\circ} \mathrm{C}$ for $48 \mathrm{~h}$ and kept cold $4^{\circ} \mathrm{C}$ for $48 \mathrm{~h}$ ) [16,17]. The physical stability of formulations was evaluated using physical parameters including physical appearance, color, odor, and homogeneity. All physical parameters were inspected through visual inspection.

\section{Measurement of $\mathrm{pH}$}

The $\mathrm{pH}$ value of the prepared formulations was measured using a digital $\mathrm{pH}$ meter. The solution of gel and ointment was dissolved in $100 \mathrm{ml}$ of distilled water and stored for $2 \mathrm{~h}$. The $\mathrm{pH}$ measurement in each formulation was done in triplicate and the average value was calculated.

\section{Viscosity}

The viscosity of gel and ointment formulations was measured using Brookfield Viscometer with the spindle. Using spindle number LV-64 at $100 \mathrm{rpm}$ and the temperature was maintained at $25 \pm 2^{\circ} \mathrm{C}$.

\section{Chemical stability test}

Chemical stability test used to detect scopoletin (standard reagent) of the formulations was carried out for 36 days by measuring at the initial day and 36 days after. At various temperature conditions including room temperature $\left(25 \pm 2^{\circ} \mathrm{C}\right)$, cold $\left(4^{\circ} \mathrm{C}\right)$, and heating-cooling cycle (kept in a hot oven at $45^{\circ} \mathrm{C}$ for $48 \mathrm{~h}$ and kept in cold temperature at $4^{\circ} \mathrm{C}$ for $48 \mathrm{~h}$ ). The chemical stability of formulations was evaluated using highperformance liquid chromatography (HPLC) [18].

\section{HPLC procedure}

A Shimadzu LC-10 was used with a UV detector set at $283 \mathrm{~nm}$ having Eclipse XDB-C18 column $(4.6 \mathrm{~mm} \times 150 \mathrm{~mm} ; 5 \mu \mathrm{m}$ I.D. $)$. The mobile phase was a mixture of $0.1 \%$ phosphoric acid and acetonitrile (82:18) with a flow rate of $1.0 \mathrm{ml} / \mathrm{min}$. The sample solution $\left(20 \mu \mathrm{l}\right.$ at $\left.35 \pm 1^{\circ} \mathrm{C}\right)$ was injected and the chromatogram was recorded. Peak area for each sample was measured and comparison was made between reference and sample solution peaks.

\section{RESULTS}

The objective of the current study is comparative studies on the physicochemical properties of M. citrifolia gel and ointment formulations.

\section{Extraction of plant material}

The simple method was used for the preparation of the extract. The percentage yield of methanolic extract of M. citrifolia was found to be $8.8 \%$.

\section{Determination of phytochemical screening}

Phytochemical screening studies of $M$. citrifolia revealed the presence of anthraquinone, cardiac glycosides, coumarins, tannins, alkaloids,

Table 1: Gel base formulation $(10 \%)$

\begin{tabular}{lll}
\hline Name of the ingredient & Quantity $(\mathrm{g})$ & Properties of ingredient \\
\hline Morinda citrifolia extract & 10.0 & Active ingredient \\
Carbopol Ultrez & 1.0 & Gelling agent \\
Propylene glycol & 1.5 & Humectant \\
Triethanolamine & 1.4 & pH adjusting agent \\
Paraben concentrate & 1.0 & Preservative \\
Deionized water & qs to 100.0 & Vehicle \\
\hline
\end{tabular}

Table 2: Ointment base formulation (10\%)

\begin{tabular}{lll}
\hline Name of the ingredient & Quantity (g) & Properties of ingredient \\
\hline Morinda citrifolia extract & 10.0 & Active ingredient \\
White petrolatum & 90.0 & Ointment base \\
\hline
\end{tabular}

Table 3: Evaluation of phytochemical screening

\begin{tabular}{ll}
\hline No. plant constituents & Results \\
\hline Anthraquinone & + \\
Cardiac glycosides & + \\
Saponin & - \\
Coumarins & + \\
Tannins & + \\
Phenols and flavonoids & + \\
Alkaloids & + \\
\hline
\end{tabular}

+: Present,-: Absent 
Table 4: Physical evaluation of gel formulation

\begin{tabular}{|c|c|c|c|c|}
\hline \multirow{2}{*}{$\begin{array}{l}\text { Physical } \\
\text { evaluation }\end{array}$} & \multirow[t]{2}{*}{ Initial } & \multicolumn{3}{|l|}{36 days after } \\
\hline & & $25 \pm 2^{\circ} \mathrm{C}$ & $4^{\circ} \mathrm{C}$ & Heating-cooling cycle \\
\hline \multicolumn{5}{|l|}{ Gel formulation } \\
\hline Physical appearance & Clear & Clear & Clear & Clear \\
\hline Color & Light brown & Dark brown & Brown & Brown \\
\hline Odor & Characteristic & Characteristic & Characteristic & Characteristic \\
\hline Homogeneity & Good & Good & Good & Good \\
\hline $\mathrm{pH}$ & $5.42 \pm 0.09$ & $5.87 \pm 0.14$ & $5.91 \pm 0.15$ & $5.89 \pm 0.21$ \\
\hline Viscosity & $11980.96 \pm 16.50$ & $11830.56 \pm 19.43$ & $12550.80 \pm 25.60$ & $14150.30 \pm 21.30$ \\
\hline
\end{tabular}

Table 5: Physical evaluation of ointment formulation

\begin{tabular}{lllll}
\hline Physical evaluation & Initial & & & \\
\cline { 3 - 4 } & & & & \\
\hline
\end{tabular}

Table 6: Chemical evaluation of gel and ointment formulation

\begin{tabular}{|c|c|c|c|c|}
\hline \multirow[t]{3}{*}{ Formulations } & \multicolumn{4}{|c|}{ Scopoletin (mg/100 g sample) } \\
\hline & \multirow[t]{2}{*}{ Initial } & \multicolumn{3}{|c|}{36 days after } \\
\hline & & $25 \pm 2^{\circ} \mathrm{C}$ & $4^{\circ} \mathrm{C}$ & Heating-cooling cycle \\
\hline Gel formulation & $16.38 \pm 0.56$ & $15.46 \pm 0.19$ & $15.81 \pm 0.09$ & $12.87 \pm 0.22 *$ \\
\hline Ointment formulation & $4.89 \pm 0.34^{*}$ & $2.58 \pm 0.06^{\dagger}$ & $3.55 \pm 0.06^{\dagger}$ & $0.90 \pm 0.02 \dagger$ \\
\hline
\end{tabular}

${ }^{*} \mathrm{p}<0.05$ when compared to gel formulation on the initial day. ${ }^{\dagger} \mathrm{p}<0.05$ when compared to ointment formulation the initial day

phenols, and flavonoids which corresponds to previous research and shows that the extracted method of this researcher is reliable. The results obtained are summarized in Table 3.

\section{Evaluation of topical gel and ointment}

\section{Physical evaluation}

All physical parameters were inspected through visual inspection. Results showed that gel formulation was found only to be changed in color (other physical parameters did not change). However, ointment formulation was found to have a change in color in all of the conditions with a homogeneity change in heating-cooling cycle condition only. The results are shown in Tables 4 and 5.

\section{Measurement of $\mathrm{pH}$}

$\mathrm{pH}$ of the gel and ointment was measured using digital $\mathrm{pH}$ meter. The gel and ointment formulations average value was about $5.77 \pm 0.15$ and $5.68 \pm 0.14$, respectively. The results are given in Tables 4 and 5 .

\section{Viscosity}

The viscosities of gel and ointment formulations were determined using Brookfield Viscometer. Measuring with all temperature conditions after 36 days, viscosities in the gel formulation did not change, but it was increased in the ointment formulation at the heating-cooling cycle condition only. The viscosities of the formulations were reported in Tables 4 and 5. 


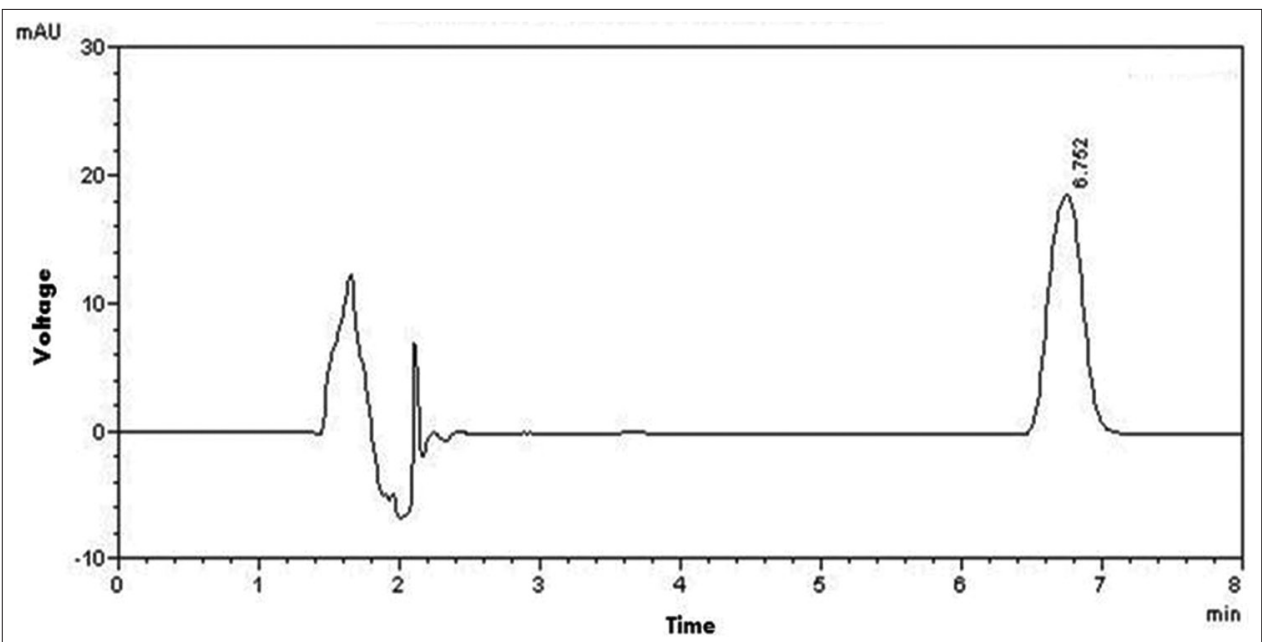

Fig. 1: Chromatogram on the initial day of scopoletin (reference)

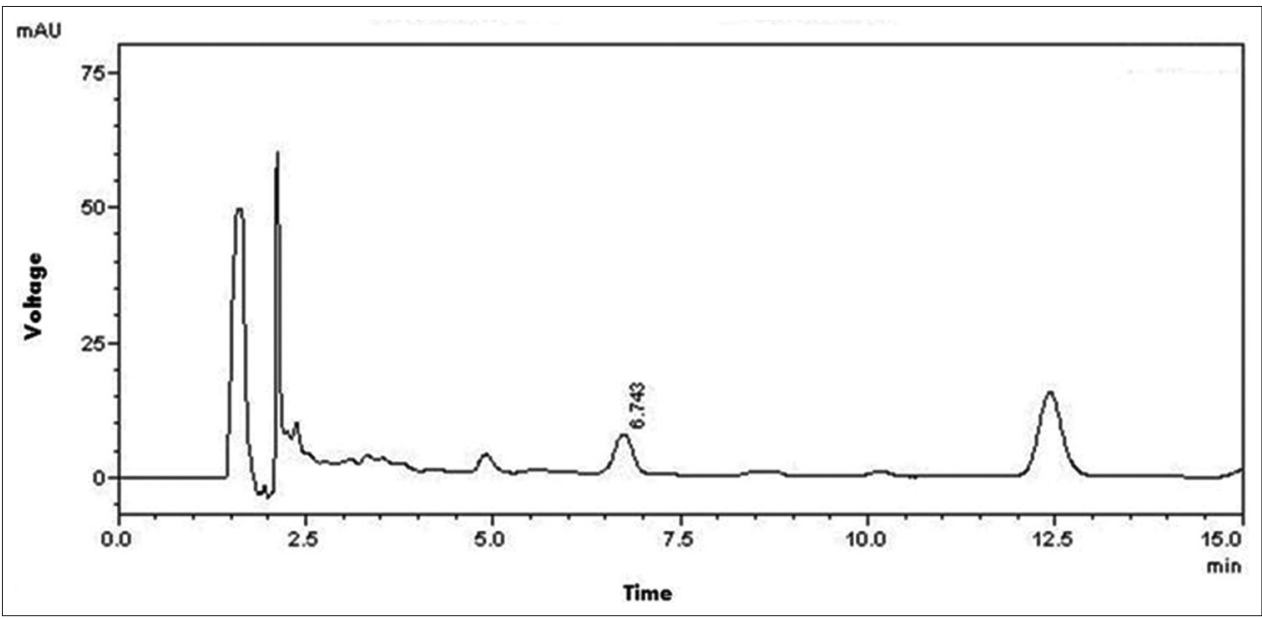

Fig. 2: Chromatogram on the initial day of gel formulation

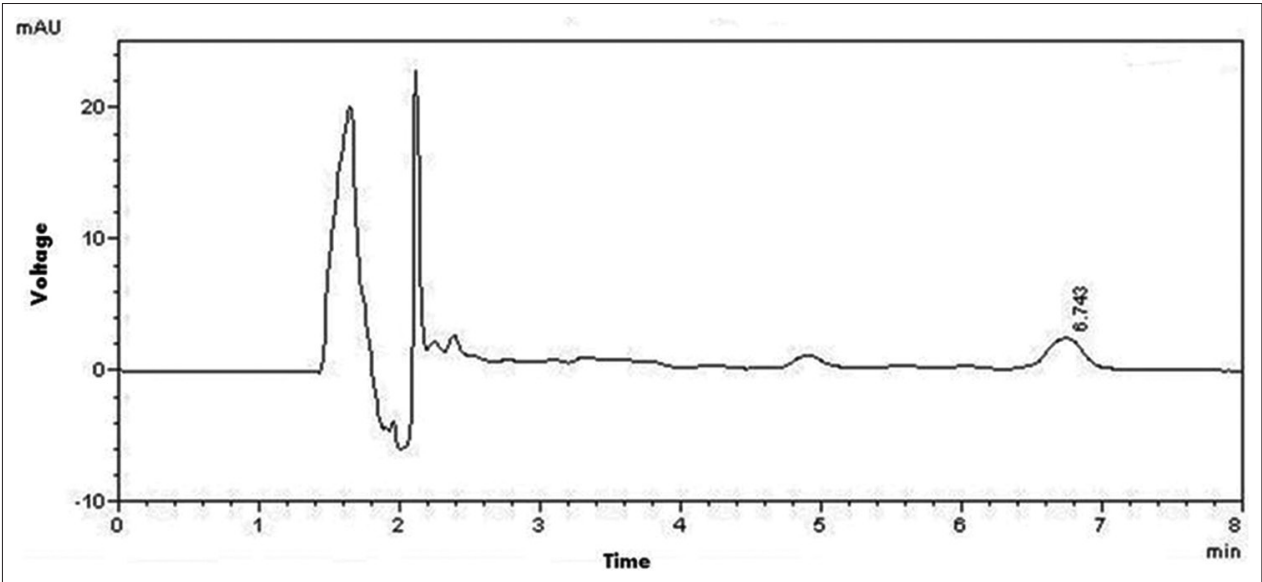

Fig. 3: Chromatogram on the initial day of ointment formulation

\section{Chemical evaluation}

The chemical stability of the formulations was evaluated by detecting and compared the amount of scopoletin at various times and temperature conditions. Results show that on the initial day, scopoletin in a gel formulation was found to be three folds higher than in ointment formulation. On day 36, scopoletin in gel formulation decreased without significant compared to the initial day at both room and cold temperature, while it had significant decrease in heating-cooling cycle conditions. Scopoletin in the ointment formulation had a significant decrease in all tested conditions. The results are shown in Figs. 1-3 and Table 6.

\section{DISCUSSION}

M. citrifolia is a widely used herb and commonly found in Southeast Asian countries. It has been used in medicine for a long time. It has 
various medicinal properties such as helping to eliminate toxins in the body, stimulate the immune system, antioxidants, anti-inflammatory antibacterial, antiviral anti-tubercular, antitumor, anthelmintic, analgesic, hypotensive, and wound healing effects. In vivo study, it supports the wound healing effect due to the found active substances in M. citrifolia extracts, namely proxeronine, scopoletin, anthraquinone, vitamins, and amino acids $[19,20]$. Those active substances play a role in reducing inflammation and wound healing [21-23]. This study found that M. citrifolia extract contains actives substances such as anthraquinone, cardiac glycosides, coumarins, tannins, alkaloids, phenols, and flavonoids which corresponds to previous research and shows that the extracted method of this researcher is reliable.

At the present, products from noni extract have various forms but the topical form, gel, or ointment, detailed information regarding its wound healing capability are not completely documented. Thus, these studies were first reported to comparative studies on the physicochemical properties of noni formulation in various conditions. Development and evaluation of M. citrifolia extract in gel and ointment formulations contain 10\% extract. Physical stability test of the formulations was carried out for 36 days by measuring in the initial ( 0 days) and the second time (36 days after) at various temperature conditions. The physical stability of formulations was evaluated using physical parameters such as physical appearance, color, odor, and homogeneity. All physical parameters were inspected through visual inspection. Results showed that gel formulation was found physical parameters did not change the only color to be changed. However, ointment formulation was found to have a change in color in all of the conditions with a homogeneity change in heating-cooling cycle condition only which change in color of gel and ointment formulation maybe caused by the oxidizing reaction. Chemical stability gets evaluated by detecting scopoletin on the initial day at various temperature conditions. The scopoletin was found to be three folds more in gel formulation than in ointment formulation. Moreover, after 36 days only at heating-cooling cycle condition found scopoletin significant decrease, but ointment formulation found scopoletin significant decrease in all conditions. The ointment formulation found scopoletin less than gel formulation maybe the formulation was a separated layer and physical appearance very hard due to the formulation not dissolve well when measured using the HPLC, its found scopoletin less. Furthermore, ointment formulation has properties of drug release lower than gel formulation [24-26]. Therefore, the detection of scopoletin found less which according to the experimental results. At heating-cooling cycle condition is not an appropriate store of this gel and ointment formulations.

\section{CONCLUSION}

Development and evaluation of M. citrifolia extract in gel and ointment formulations; based on the results of all experiments, it can be said that gel formulation is suitable for development due to its physical and chemical stability results which were better than ointment formulation results. Thus, gel formulation could become a media to be used for its medicinal properties. Results found in this research can be used as the base for further development of the gel formulation to obtain a formulation that can be used in drugs or in the form of topical treatment for wound healing or anti-inflammation effect.

\section{ACKNOWLEDGMENTS}

The authors are grateful to the Pharmacology and Toxicology Unit, Faculty of Science, Rangsit University. The authors also extend their thanks to Natcha Muaengkaew and Phraophirat Sompet, for their technical support and the researcher Nirun Vipunngeun assisted in plant identification. This work was funded by Rangsit University. Grant no. 5/2561.

\section{AUTHORS' CONTRIBUTIONS}

Pataweekorn Ketkomol conceived and designed the analysis, collected the data and performed the analysis. Tadsanee Punjanon supervised the findings of this work. All authors discussed the results and contributed to the final manuscript.

\section{CONFLICTS OF INTEREST}

The authors declare that they have no conflicts of interest.

\section{REFERENCES}

1. Naira N, Karvekar MD. Wound healing: A review. Int J Appl Bio Pharm Tech 2010;1:1369-77.

2. Kumar B, Vijayakumar M, Govindarajan R, Pushpangadan P. Ethnopharmacological approaches to wound healing exploring medicinal plants of India. J Ethnopharmacol 2007;114:103-13.

3. Strodtbeck F. Physiology of wound healing. Newborn Infant Nurs Rev 2001;1:43-52.

4. Lokesh P, Kalaskar PG, Chandrasekar SB, Umashankar C, Pawar, AT. Formulation and evaluation of herbal formulations (ointment, cream, gel) containing Tridax procumbens and Areca catachu. J Sci Innov Res 2017;6:97-100

5. 6. Levand O, Larson HO. Some chemical constituents of Morinda citrifolia. Planta Med 1979;36:186-7.

7. Silvia S, Annisa A. Formulation of anti-wrinkle hydrogel face mask containing ethanol extract of noni fruit (Morinda citrifolia L.) for use a nutra cosmeceutical product. Int J Appl Pharm 2017;9:74-6.

8. Wang MY, Anderson G, Nowicki D, Jensen J. Hepatic protection by noni fruit juice against $\mathrm{CCl} 4$-induced chronic liver damage in female SD rats. Plant Foods Hum Nutr 2008a;3:141-7.

9. Yuslianti ER, Sabirin IP, Sovia E. Effect of topical ethanol extracts of Morinda citrofilia L. Leaves on excisional wound healing. Int J Pharmacol 2013;9:318-21.

10. Palu A, Su C, Zhou BN, West B, Jensen J. Wound healing effects of noni (Morinda citrifolia L.) leaves: A mechanism involving its PDGF/A2A receptor ligand binding and promotion of wound closure. Phytother Res 2010;24:1437-41

11. Gajalakshmi S, Vijayalakshmi S, Devirajeswari V. Phytochemical and pharmacological properties of Annona muricata: Review. Int J Pharm Pharm Sci 2012;4:3-6.

12. Avinash S, Gowda DV, Suresh J, Aravind RA, Atul S, Riyaz AM. Formulation and evaluation of topical gel using Eupatorium glandulosum Michx. For wound healing activity. Scholars Res Libr Der Pharm Lett 2016;8:255-66.

13. Conners KA, Amidon GL, Stella VJ. Chemical Stability of Pharmaceuticals-A Handbook for Pharmacists. $2^{\text {nd }}$ ed. New York: John Wiley and Sons Inc.; 1986. p. 456-82.

14. Evans WC. Trease and Evan's Pharmacognosy. London: WB Saunders; 2002.

15. Kokate CK, Purohit AP, Gokhale SB. Methods of crude drug evaluation. Pharmacogn Nirali Prakasan Pune 1995;10:88-99.

16. Manimaran S, Nithya W, Praveen, TK. Development and screening of topical herbal cream formulations for antimicrobial and wound healing activity. Nat Prod Sci 2014;5:383-8.

17. Kang MH, Kim BH. Oral wound healing effects of acai berry water extracts in rat oral mucosa. Toxicol Res 2018;34:97-102.

18. Nithya M, Suguna L, Rose C. The effect of nerve growth factor on the early responses during the process of wound healing. Biochim Biophys Acta 2003;1620:25-31

19. Panyarajun S. Experimental Pharmacognosy L. Bangkok: Rangsit University; 1996. p. 56-82.

20. Rajasree PH, Vishwanad V, Cherian M, Eldhos, J, Singh R. Formulation and evaluation of antiseptic polyherbal ointment. Int J Pharm Life Sci 2012:3:2021-31.

21. Sumitra C. Importance of pharmacognostic study of medicinal plants: An overview. J Pharmacogn Phytochem 2014;2:69-73.

22. Vijayapandi P, Megala N, Thubasni K, Dharmani DM, Zahurin M. Effect of noni(Morinda citrifolia Linn.) fruit and its bioactive principles scopoletin and rutin on rat vas deferens contractility: An ex vivo study. Sci World J 2014;8:1-11.

23. McKay IA, Leigh IM. Epidermal cytokines and their roles in cutaneous wound healing. Br J Dermatol 1991;124:513-8.

24. Negi A, Sharma N, Singh MF. J Pharmacogn Phytochem 2012;1:201-33.

25. Muhmoud MA. Effect of different formulation variables on release characteristics of gastro-floating microspheres of ethyl cellulose/ carbopol 934P encapsulating sorafenib. Int J Pharm Pharm Sci 2019; $11: 64-70$

26. Hirihattaya P, Somchai S. Development of cosmetic cream containing a pharmaceutical cocrystal of salicylic and phenylalanine. Int J Appl Pharm 2019;11:1-11. 